Published in final edited form as:

Am J Obstet Gynecol. 2017 July ; 217(1): 49.e1-49.e10. doi:10.1016/j.ajog.2017.03.001.

\title{
Disparities in the Management of Ectopic Pregnancy
}

Jennifer Y. HSU, MD ${ }^{1}$, Ling CHEN, MD, MPH ${ }^{1}$, Arielle R. GUMER, MD ${ }^{1}$, Ana I. TERGAS, MD $^{1,3,4,5}$, June Y. HOU, MD ${ }^{1,4,5}$, William M. BURKE, MD ${ }^{1,4,5}$, Cande V. ANANTH, PhD, MPH $^{1,3}$, Dawn L. HERSHMAN, MD ${ }^{2,3,4,5}$, and Jason D. WRIGHT, MD ${ }^{1,4,5}$

${ }^{1}$ Department of Obstetrics and Gynecology, Columbia University College of Physicians and Surgeons

2Department of Medicine, Columbia University College of Physicians and Surgeons

${ }^{3}$ Department of Epidemiology, Mailman School of Public Health, Columbia University

${ }^{4}$ Herbert Irving Comprehensive Cancer Center, Columbia University College of Physicians and Surgeons

${ }^{5}$ New York Presbyterian Hospital

\section{Abstract}

Background-Ectopic pregnancy is common among young women. Treatment can consist of either surgery with salpingectomy or salpingostomy or medical management with methotrexate. In addition to acute complications, treatment of ectopic pregnancy can result in long term sequelae including decreased fertility. Little is known about the patterns of care and predictors of treatment in women with ectopic pregnancy. Similarly, data on outcomes for various treatments are limited.

Objective-We examined the patterns of care and outcomes for women with ectopic pregnancy. Specifically, we examined predictors of medical (vs. surgical) management of ectopic pregnancy and tubal conservation (salpingostomy vs. salpingectomy) among women who underwent surgery.

Study Design-The Perspective database was used to identify women with a diagnosis of tubal ectopic pregnancy treated from 2006-2015. Perspective is an all-payer database that collects data on patients at hospitals from throughout the U.S. Women were classified as having undergone medical management if they received methotrexate and surgical management if treatment consisted of salpingostomy or salpingectomy. Multivariable models were developed to examine predictors of medical treatment and of tubal conserving salpingostomy among women treated surgically.

Results-Among the 62,588 women, 49,090 (78.4\%) were treated surgically and 13,498 (21.6\%) received methotrexate. Use of methotrexate increased from $14.5 \%$ in 2006 to $27.3 \%$ by 2015 $(\mathrm{P}<0.001)$. Among women who underwent surgery, salpingostomy decreased over time from

Corresponding Author: Jason D. Wright, M.D., Division of Gynecologic Oncology, Department of Obstetrics and Gynecology, Columbia University College of Physicians and Surgeons, 161 Fort Washington Ave, $8{ }^{\text {th }}$ Floor, New York, NY 10032, Telephone: (212) 305-3410, Fax: (212) 305-3412, jw2459@ columbia.edu.

Publisher's Disclaimer: This is a PDF file of an unedited manuscript that has been accepted for publication. As a service to our customers we are providing this early version of the manuscript. The manuscript will undergo copyediting, typesetting, and review of the resulting proof before it is published in its final citable form. Please note that during the production process errors may be discovered which could affect the content, and all legal disclaimers that apply to the journal pertain. 
$13.0 \%$ in 2006 to $6.0 \%$ in 2015 ( $\mathrm{P}<0.001)$. Treatment in more recent years, at a teaching hospital, and at higher volume centers were associated with increased use of methotrexate $(\mathrm{P}<0.05$ for all). In contrast, Medicaid recipients ( $\mathrm{aRR}=0.92 ; 95 \% \mathrm{CI}, 0.87-0.98)$ and uninsured women $(\mathrm{aRR}=0.87 ; 95 \% \mathrm{CI}, 0.82-0.93)$ were less likely to receive methotrexate than commercially insured patients. Among those who underwent surgery, black (aRR=0.76; 95\% CI, 0.69-0.85) and Hispanic $(\mathrm{aRR}=0.80 ; 95 \% \mathrm{CI}, 0.66-0.96)$ patients were less likely to undergo tubal conserving surgery than white women and Medicaid recipients $(\mathrm{aRR}=0.69 ; 95 \% \mathrm{CI}, 0.64-0.75)$ and uninsured women $(\mathrm{aRR}=0.60 ; 95 \% \mathrm{CI}, 0.55-0.66)$ less frequently underwent salpingostomy than commercial insured patients.

Conclusion-There is substantial variation in the management of ectopic pregnancy. There are significant racial and insurance related disparities associated with treatment.

\section{Keywords}

Disparities; ectopic pregnancy; methotrexate; salpingectomy; salpingostomy

\section{Introduction}

The incidence of ectopic pregnancy, defined as the implantation of a fertilized ovum outside of the endometrium, varies between $1-2 \%$ in the general population. ${ }^{1,2}$ Despite advances in early diagnosis and management, complications arising from ectopic pregnancy remain a significant cause of morbidity and mortality in the first trimester. Using pregnancy-related mortality estimates between 1991-1999, the rate of death was calculated to be 31.9 per 100,000 cases of ectopic pregnancy. ${ }^{3}$ In addition to acute morbidity, ectopic pregnancy may decrease future fertility.

Women with ectopic pregnancy are typically managed either medically with methotrexate or surgically. Methotrexate is administered via intramuscular injection and offers a noninvasive route of treatment. Surgical treatment most commonly consists of either salpingectomy or salpingostomy with tubal preservation. With conservative management via methotrexate or salpingostomy, close follow-up with serial measurements of quantitative beta human chorionic gonadotropin is imperative to ensure resolution. ${ }^{4}$

Multiple clinical criteria are used to evaluate the suitability of patients for medical versus surgical management ${ }^{5}$. There is recent data promoting the benefits of tubal conservation to optimize future fertility without excessive risk of recurrent ectopic pregnancy. ${ }^{6,7}$ However, data are conflicting with regard to actual fertility outcomes in cases of tubal conservation, with some studies suggesting no difference in intrauterine pregnancy rates between conservative management and salpingectomy, ${ }^{7-9}$ but others reflecting significant improvement in fertility with conservative management. ${ }^{6}$ At minimum, the results support a thoughtful discussion with patients about the risk-benefit calculus in the context of their reproductive goals and personal preferences.

To date, little is known about the patterns of care for management of ectopic pregnancy in the United States. We performed a population-based analysis to examine the patterns of care and outcomes for women with ectopic pregnancy. Specifically, we examined factors 
associated with medical management of ectopic pregnancy and tubal conservation among women who underwent surgery.

\section{Methods}

\section{Patients and Procedures}

We used the Perspective database (Premier, Charlotte, NC) to identify women 15-60 years of age with ectopic pregnancy treated from 2006 to the first quarter of 2015. This all-payer database captures insurance claims data from over 500 acute care hospitals, representing approximately $15 \%$ of hospitalizations nationally. ${ }^{10}$ Hospitals included in the dataset report data on all patients treated within the given facility (inpatient and outpatient). Perspective captures data on clinical and demographic characteristics of patients and diagnoses and procedures billed through ICD-9 codes. Additionally, Perspective captures drugs received by patients and services rendered through capture of billing and utilization codes.

Treatment was classified as either medical with methotrexate, or surgical with salpingostomy or salpingectomy. Methotrexate use was identified from hospital billing records, while salpingostomy (ICD-9 66.01, 66.02) and salpingectomy (ICD-9 65.41, 65.49, $66.4,66.5,66.51,66.52,66.62,66.63,66.69)$ were identified based on ICD-9 procedure codes. Patients with codes for both salpingostomy and salpingectomy were classified as having undergone salpingectomy.

Demographic and clinical data included age at the time of the treatment $(<20,20-24,25-29$, 30-34, 35-39, 40-44, and $\geq 45$ years), year of the treatment, marital status (married, single, and other/unknown), and primary insurance status (commercial, Medicare, Medicaid, uninsured, and unknown). Race was self-reported and categorized as white, black, Hispanic, and other/unknown. Tbe Elixhauser comorbidity index, a measure of underlying medical comorbidity based on defined coding, was used to classify comorbid diseases in patients. The index was classified into 0,1 , and $\geq 2$ based on the number of comorbid medical conditions.

Hospitals were categorized based on location (urban or rural), teaching status (teaching or non-teaching), hospital bed size ( $<400,400-600$, and $>600$ beds), and region of the country defined within the dataset (Northeast, Midwest, West, and South). Annualized hospital volume was calculated for each hospital and estimated as 4 times the quarterly mean of the number of patients with any treatment at a given hospital.

\section{Outcomes}

The outcomes of the analysis included medical vs. surgical treatment, and salpingostomy vs. salpingectomy among women treated surgically. A composite metric of any complication was analyzed among surgical patients and included hemorrhage, venous thromboembolism, shock, transfusion, renal failure, respiratory failure, bacteremia, sepsis, pneumonia, other infection, and other complications. 


\section{Statistical Analysis}

The demographic and clinical characteristics were compared between women with medical vs. surgical treatment, and between salpingostomy vs. salpingectomy using $\chi^{2}$ and Wilcoxon rank-sum tests. Trends in treatment were compared using Cochran-Armitage trend test. To examine predictors of medical treatment, generalized estimating equations (GEE) including all demographic and clinical characteristics available in the dataset were used to account for hospital-level clustering. Given that prior studies of other surgical procedures have often noted that race and insurance status are associated with treatment choice, a priori we hypothesized that these factors may also be associated with treatments for ectopic pregnancy. However, given the limited prior data describing predictors of treatment for ectopic pregnancy, we included all of the clinical, demographic, and hospital characteristics in our multivariable models. Similar GEE models were developed to examine predictors of salpingostomy and complications among women who underwent surgical treatment. All analyses were conducted with SAS, version 9.4 (SAS Institute, Cary, NC). All statistical tests were two-sided. A P-value of $<0.05$ was considered statistically significant.

\section{Results}

Among the 62,588 women identified with ectopic pregnancy, 49,090 (78.4\%) underwent surgery with salpingectomy or salpingostomy, while 13,498 (21.6\%) received medical management with methotrexate. As can be seen in Figure 1A, use of methotrexate increased significantly from $14.5 \%$ in 2006 to $27.3 \%$ by 2015 while surgical management declined from $85.5 \%$ to $72.7 \%$ over the same time period $(\mathrm{P}<0.001)$. Among those women who underwent surgery, salpingostomy decreased over time from $13.0 \%$ in 2006 to $6.0 \%$ in 2015 while the rate of salpingectomy rose from $87.0 \%$ to $94.0 \%$ over the time period $(\mathrm{P}<0.001)$ (Figure 1B).

Table 1 displays the clinical and demographic characteristics of the cohort stratified by receipt of methotrexate or surgery. Treatment in more recent years, management at a teaching hospital and treatment at higher volume centers were associated with increased use of methotrexate ( $\mathrm{P}<0.05$ for all). Compared to women treated at a non-teaching facility, patients at teaching hospitals were $16 \%$ more likely to receive methotrexate $(\mathrm{aRR}=1.16$; $95 \%$ CI, 1.02-1.33). In contrast, women with non-commercial insurance were less likely to receive methotrexate. Compared to women with commercial insurance, Medicaid recipients were $8 \%(\mathrm{aRR}=0.92 ; 95 \% \mathrm{CI}, 0.87-0.98)$ less likely and uninsured women $13 \%(\mathrm{aRR}=0.87$; 95\% CI, 0.82-0.93) less likely to receive methotrexate.

Factors associated with salpingostomy among women who underwent surgery are displayed in Table 2. Older age, more recent year of treatment, the presence of medical comorbidities, non-white race, and non-commercial insurance coverage were all associated with a decreased likelihood of undergoing salpingostomy. Compared to white women, black $(\mathrm{aRR}=0.76 ; 95 \% \mathrm{CI}, 0.69-0.85)$ and Hispanic $(\mathrm{aRR}=0.80 ; 95 \% \mathrm{CI}, 0.66-0.96)$ patients were less likely to undergo tubal conserving surgery. Similarly, Medicaid recipients ( $\mathrm{aRR}=0.69$; 95\% CI, 0.64-0.75) and uninsured women ( $\mathrm{aRR}=0.60 ; 95 \% \mathrm{CI}, 0.55-0.66)$ less frequently underwent salpingostomy than commercial insured patients. In contrast, compared to women residing in the Northeastern U.S., patients in the Midwest $(\mathrm{aRR}=1.51 ; 95 \%$ CI, 
1.20-1.88) and West (aRR=1.62; 95\% CI, 1.26-2.08) were more likely to undergo salpingostomy.

The overall perioperative complication rate was $23.4 \%$ (95\% CI, 22.3-24.5\%) among women who underwent salpingostomy and 34.9\% (95\% CI, 34.5-35.4\%) after salpingectomy (Table 3). Hemorrhage was the most frequent complication. In a multivariable model, complications remained $31 \%$ less common after salpingostomy (aRR=0.69; 95\% CI 0.65-0.73) (Table 4). Older women were less likely than younger women to experience a complication, while Hispanic (compared to white) women $(\mathrm{aRR}=1.15 ; 95 \% \mathrm{CI} 1.07-1.24)$, and uninsured patients (compared to commercial insurance) $(\mathrm{aRR}=1.12 ; 95 \%$ CI $1.07-1.17)$ were more likely to experience a complication.

\section{Discussion}

We noted substantial variation in the management of ectopic pregnancy in the U.S. While the rate of medical management with methotrexate is increasing, among women who undergo surgery, tubal-conserving salpingostomy is being utilized less frequently. There are significant racial and insurance related disparities associated with treatment.

First reported in 1985, medical management of ectopic pregnancy with methotrexate works via antagonism of the folic acid pathway in DNA replication, which impairs growth of the developing trophoblast. ${ }^{11,12}$ The optimal regimen of systemic methotrexate is debated, though data suggest that the single-dose regimen is as effective as the multi-dose regimen and is associated with lower cost and fewer side effects. ${ }^{13-15}$ Wider availability of methotrexate and use of early sonography have facilitated the growth in medical management, as also seen in other studies. ${ }^{16}$ When surgical management is selected, the decision of salpingostomy versus salpingectomy is often based on surgeon preference, patient history, and intraoperative appearance of the tubes, but when factoring in costeffectiveness, recurrence risk, and future fertility, neither appears clearly superior. ${ }^{4,6-9,17}$

Prior studies have shown that minority women are not only at increased risk for the occurrence of ectopic pregnancy, but are also more likely to experience adverse outcomes. ${ }^{18,19}$ Among Medicaid recipients in New York, California, and Illinois, the relative risk for ectopic pregnancy among black women was 1.26 compared to white women between 2000-2003. ${ }^{20}$ Furthermore, the risk of death from ectopic pregnancy was 6.8 times higher for black women compared to white women during 2003-2007. ${ }^{21}$ While more severe underlying pathology in underserved minorities may account for a portion of the variation in care that we noted, pathologic differences are unlikely to account for all of the variability we noted.

There has been little prior work examining disparities in the medical and surgical treatment of ectopic pregnancy. ${ }^{19}$ Using the Nationwide Inpatient Sample, Papillon-Smith and colleagues analyzed the treatment of 35,000 women with ectopic pregnancy. The investigators found that Asian/Pacific Islanders and those treated in rural hospitals were less likely to undergo non-surgical management. ${ }^{22}$ This study was limited in that the data source only captures inpatient encounters. We noted that uninsured women and Medicaid recipients 
were less likely to receive treatment with methotrexate and were less likely to undergo salpingostomy, while black women and Hispanics were also less likely to receive tubal conserving surgery.

The reasons underlying the disparities seen in our study group, as throughout the obstetric and gynecologic literature, are complex and myriad. Without reliable insurance coverage, women often suffer delays in access to health care, leading to more advanced disease at initial presentation and, thus, greater risk of morbidity and mortality. This may help explain why uninsured women suffered more complications in our study population. Early diagnosis and treatment is particularly crucial, as a small, unruptured ectopic pregnancy affords women more choice in management, and allows them to avoid surgery where preferred. Additional rationale for the greater incidence of salpingectomy among racial minorities may be the preponderance of gonorrhea and chlamydia infections, as black women are 7 times more likely to contract chlamydia and 14 times more likely to contract gonorrhea compared to white women, likely leading to more severe underlying tubal disease related to pelvic inflammatory disease. ${ }^{23,24}$ Finally, little is known about patient preferences and patient reported outcomes for women with ectopic pregnancy. This is clearly an area that warrants further study.

We recognize a number of important limitations. First, administrative data lack many important clinical characteristics that influence treatment selection such as hemodynamic stability, beta-hCG levels, and the size of the ectopic pregnancy. A priori, the goal of our study was not to examine the effectiveness of treatment, but rather explore overall patterns of care. Second, current ICD-9 coding does not allow for the accurate distinction of laparoscopy or laparotomy. Third, we cannot exclude the possibility that treatment was misclassified in a small number of women. Likewise, although we selected women with a specific code for a tubal ectopic pregnancy, some women with a pregnancy of unknown location may have been misclassified. Fourth, as most complications from methotrexate are not acute and are documented in the outpatient setting we did not analyze these side effects. Lastly, as with any study of claims data, we lack data on physician and patient preferences, including future fertility goals, that undoubtedly influenced decision-making.

In conclusion, our study highlights inequities in health care delivery systems for the treatment of ectopic pregnancy. Further investigation to better understand the mechanisms underlying the disparities we noted is needed. Ultimately, targeted interventions to reduce the morbidity associated with the treatment of ectopic pregnancy are needed.

\section{Acknowledgments}

The authors report no conflicts of interest.

Dr. Wright (NCI R01CA169121-01A1) and Dr. Hershman (NCI R01 CA166084) are recipients of grants) from the National Cancer Institute.

\section{References}

1. Farquhar CM. Ectopic pregnancy. Lancet. 2005; 366:583-91. [PubMed: 16099295] 
2. Barnhart KT. Clinical practice. Ectopic pregnancy. N Engl J Med. 2009; 361:379-87. [PubMed: 19625718]

3. Grimes DA. Estimation of pregnancy-related mortality risk by pregnancy outcome, United States, 1991 to 1999. Am J Obstet Gynecol. 2006; 194:92-4. [PubMed: 16389015]

4. Hajenius PJ, Mol F, Mol BW, Bossuyt PM, Ankum WM, van der Veen F. Interventions for tubal ectopic pregnancy. Cochrane Database Syst Rev. 2007:CD000324. [PubMed: 17253448]

5. Capmas P, Bouyer J, Fernandez H. Treatment of ectopic pregnancies in 2014: new answers to some old questions. Fertil Steril. 2014; 101:615-20. [PubMed: 24559615]

6. de Bennetot M, Rabischong B, Aublet-Cuvelier B, et al. Fertility after tubal ectopic pregnancy: results of a population-based study. Fertil Steril. 2012; 98:1271-6. e1-3. [PubMed: 22818285]

7. Fernandez H, Capmas P, Lucot JP, et al. Fertility after ectopic pregnancy: the DEMETER randomized trial. Hum Reprod. 2013; 28:1247-53. [PubMed: 23482340]

8. Mol F, van Mello NM, Strandell A, et al. Salpingotomy versus salpingectomy in women with tubal pregnancy (ESEP study): an open-label, multicentre, randomised controlled trial. Lancet. 2014; 383:1483-9. [PubMed: 24499812]

9. Li J, Jiang K, Zhao F. Fertility outcome analysis after surgical management of tubal ectopic pregnancy: a retrospective cohort study. BMJ Open. 2015; 5:e007339.

10. Lindenauer PK, Pekow PS, Lahti MC, Lee Y, Benjamin EM, Rothberg MB. Association of corticosteroid dose and route of administration with risk of treatment failure in acute exacerbation of chronic obstructive pulmonary disease. JAMA. 2010; 303:2359-67. [PubMed: 20551406]

11. van Mello NM, Mol F, Ankum WM, Mol BW, van der Veen F, Hajenius PJ. Ectopic pregnancy: how the diagnostic and therapeutic management has changed. Fertil Steril. 2012; 98:1066-73. [PubMed: 23084008]

12. Chotiner HC. Nonsurgical management of ectopic pregnancy associated with severe hyperstimulation syndrome. Obstet Gynecol. 1985; 66:740-3. [PubMed: 3932909]

13. Lipscomb GH, Givens VM, Meyer NL, Bran D. Comparison of multidose and single-dose methotrexate protocols for the treatment of ectopic pregnancy. Am J Obstet Gynecol. 2005; 192:1844-7. discussion 7-8. [PubMed: 15970826]

14. Stovall TG, Ling FW. Single-dose methotrexate: an expanded clinical trial. Am J Obstet Gynecol. 1993; 168:1759-62. discussion 62-5. [PubMed: 8317518]

15. Alleyassin A, Khademi A, Aghahosseini M, Safdarian L, Badenoosh B, Hamed EA. Comparison of success rates in the medical management of ectopic pregnancy with single-dose and multipledose administration of methotrexate: a prospective, randomized clinical trial. Fertil Steril. 2006; 85:1661-6. [PubMed: 16650421]

16. Hoover KW, Tao G, Kent CK. Trends in the diagnosis and treatment of ectopic pregnancy in the United States. Obstet Gynecol. 2010; 115:495-502. [PubMed: 20177279]

17. Mol F, van Mello NM, Strandell A, et al. Cost-effectiveness of salpingotomy and salpingectomy in women with tubal pregnancy (a randomized controlled trial). Hum Reprod. 2015; 30:2038-47. [PubMed: 26173606]

18. Stulberg DB, Cain L, Dahlquist IH, Lauderdale DS. Ectopic pregnancy morbidity and mortality in low-income women, 2004-2008. Hum Reprod. 2016

19. Stulberg DB, Zhang JX, Lindau ST. Socioeconomic disparities in ectopic pregnancy: predictors of adverse outcomes from Illinois hospital-based care, 2000-2006. Matern Child Health J. 2011; 15:234-41. [PubMed: 20177756]

20. Stulberg DB, Cain LR, Dahlquist I, Lauderdale DS. Ectopic pregnancy rates in the Medicaid population. Am J Obstet Gynecol. 2013; 208:274e1-7. [PubMed: 23313717]

21. Creanga AA, Shapiro-Mendoza CK, Bish CL, Zane S, Berg CJ, Callaghan WM. Trends in ectopic pregnancy mortality in the United States: 1980-2007. Obstet Gynecol. 2011; 117:837-43. [PubMed: 21422853]

22. Papillon-Smith J, Imam B, Patenaude V, Abenhaim HA. Population-based study on the effect of socioeconomic factors and race on management and outcomes of 35,535 inpatient ectopic pregnancies. J Minim Invasive Gynecol. 2014; 21:914-20. [PubMed: 24768977]

23. Newman LM, Berman SM. Epidemiology of STD disparities in African American communities. Sex Transm Dis. 2008; 35:S4-12. [PubMed: 18971796] 
24. Seifer DB, Zackula R, Grainger DA. Society for Assisted Reproductive Technology Writing Group $\mathrm{R}$. Trends of racial disparities in assisted reproductive technology outcomes in black women compared with white women: Society for Assisted Reproductive Technology 1999 and 2000 vs. 2004-2006. Fertil Steril. 2010; 93:626-35. [PubMed: 19368916] 
Figure 1A

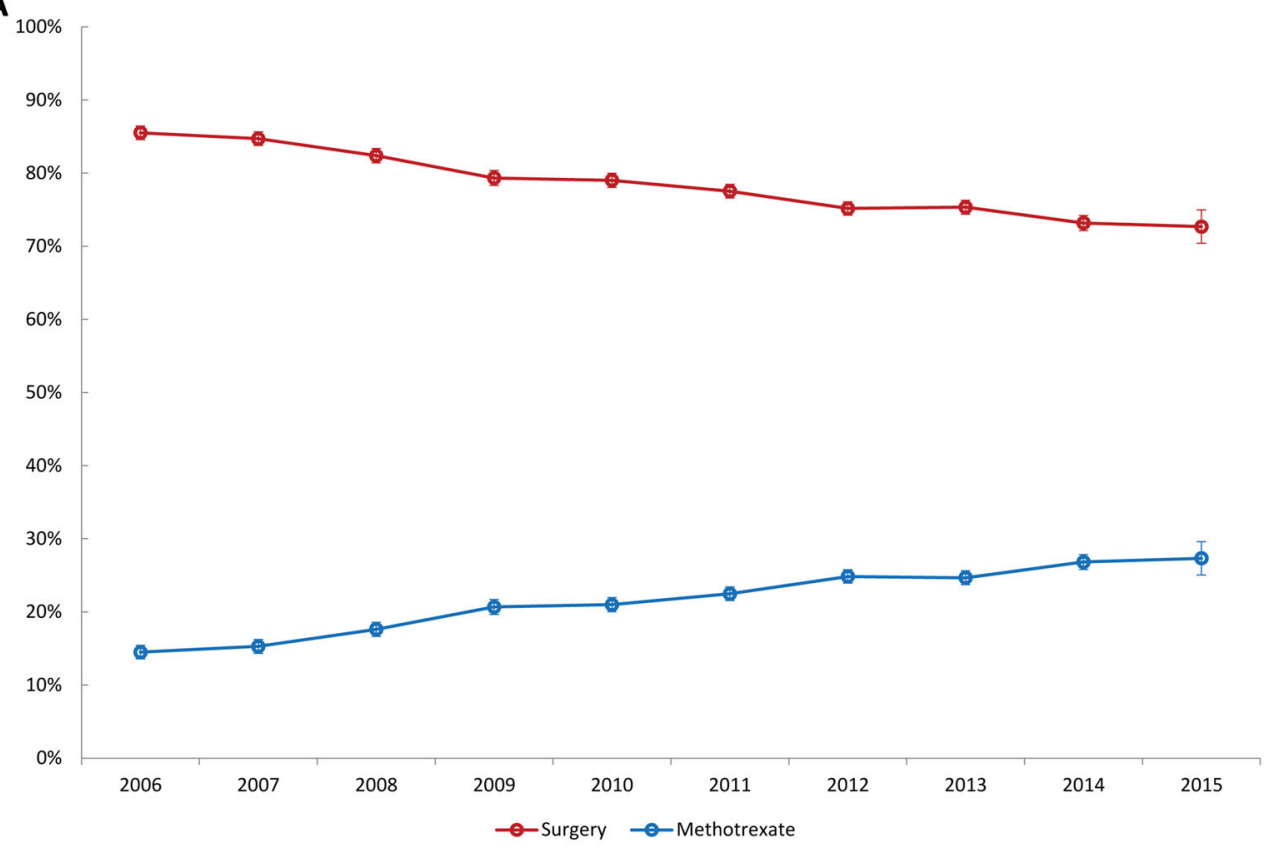

Figure 1B ${ }_{100 \%}$

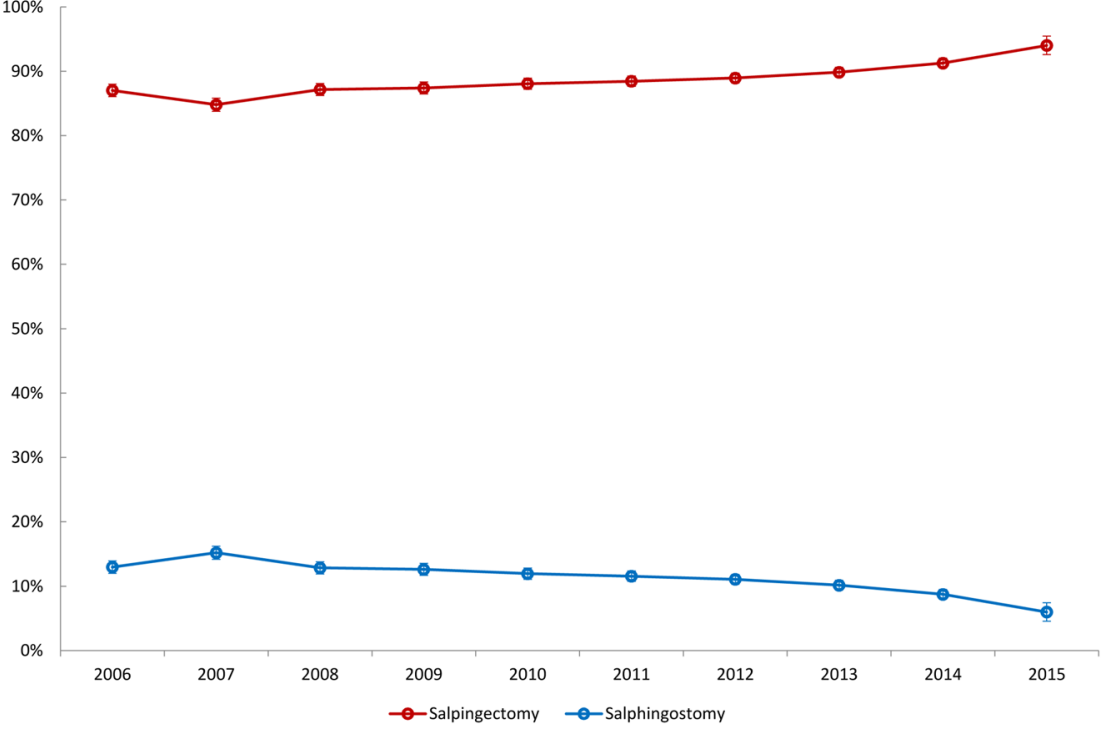

Figure 1.

Figure 1A. Use of medical versus surgical treatment for ectopic pregnancy. Figure 1B. Use of salpingectomy versus salpingostomy among women with ectopic pregnancy who underwent surgical management.

Am J Obstet Gynecol. Author manuscript; available in PMC 2018 July 01. 


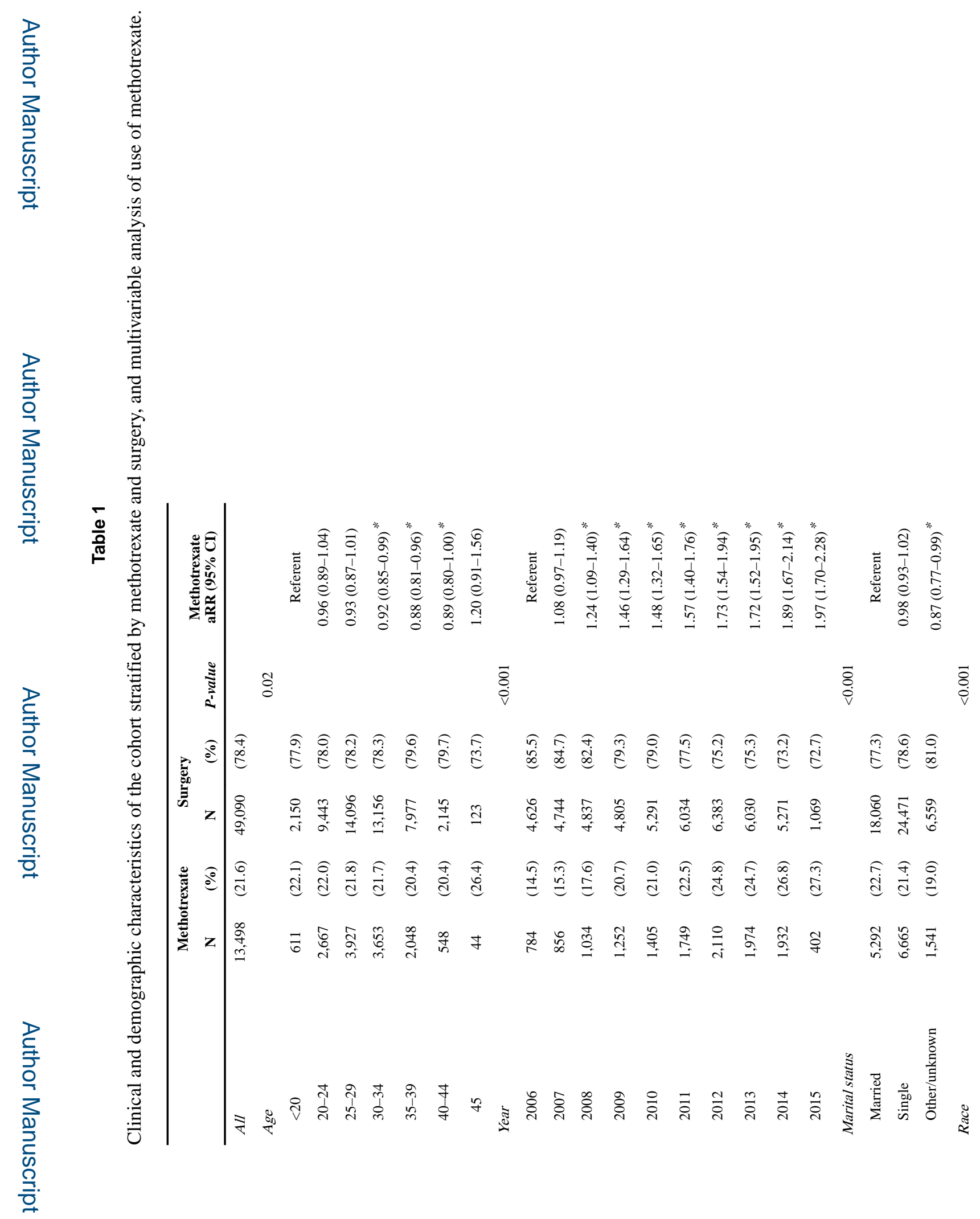
Am J Obstet Gynecol. Author manuscript; available in PMC 2018 July 01. 
HSU et al.

Page 11

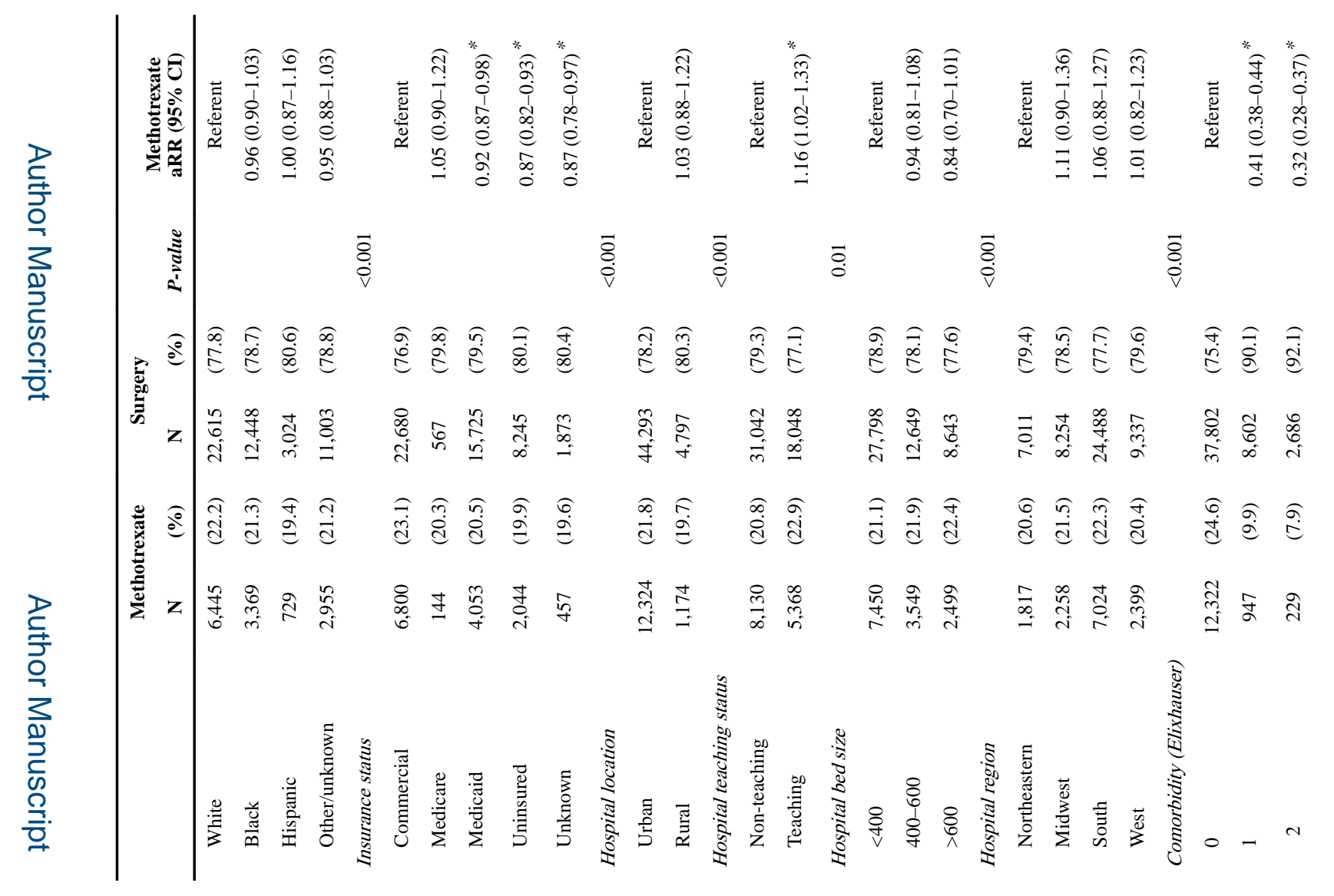

로을

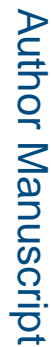

Am J Obstet Gynecol. Author manuscript; available in PMC 2018 July 01. 
HSU et al.

Page 12
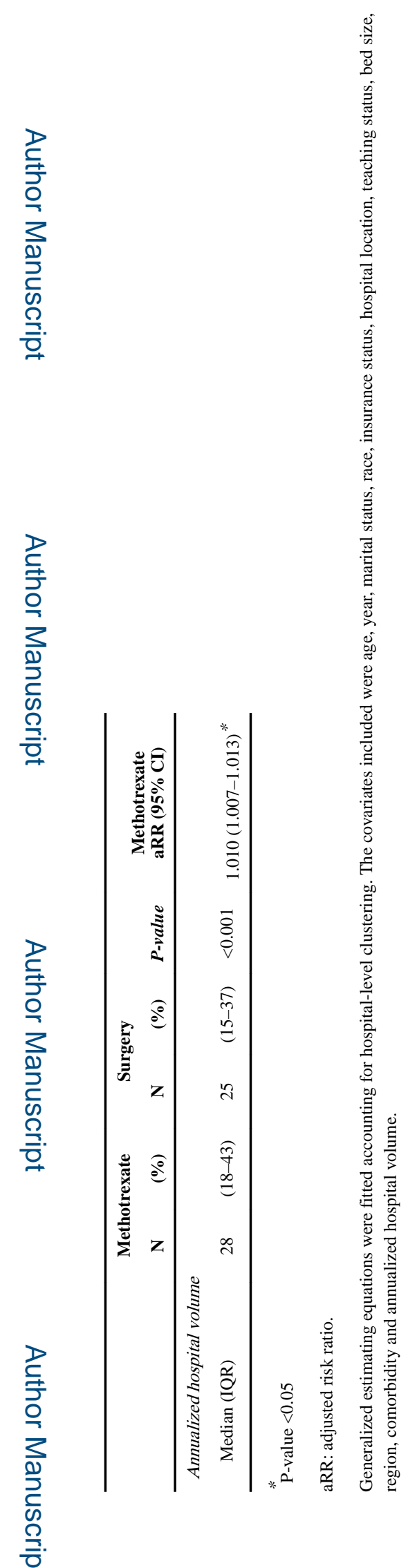

Am J Obstet Gynecol. Author manuscript; available in PMC 2018 July 01. 


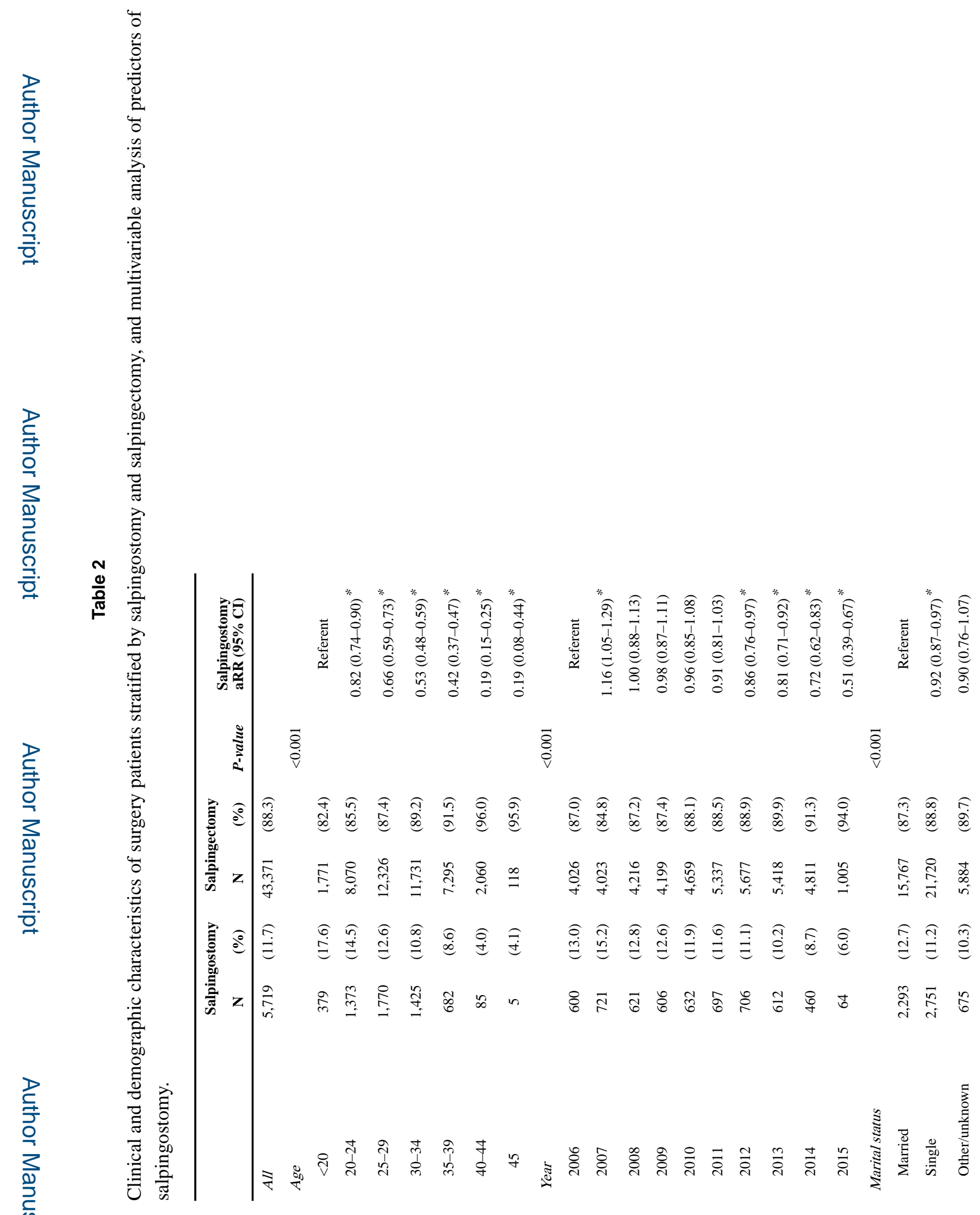


HSU et al.

Page 14

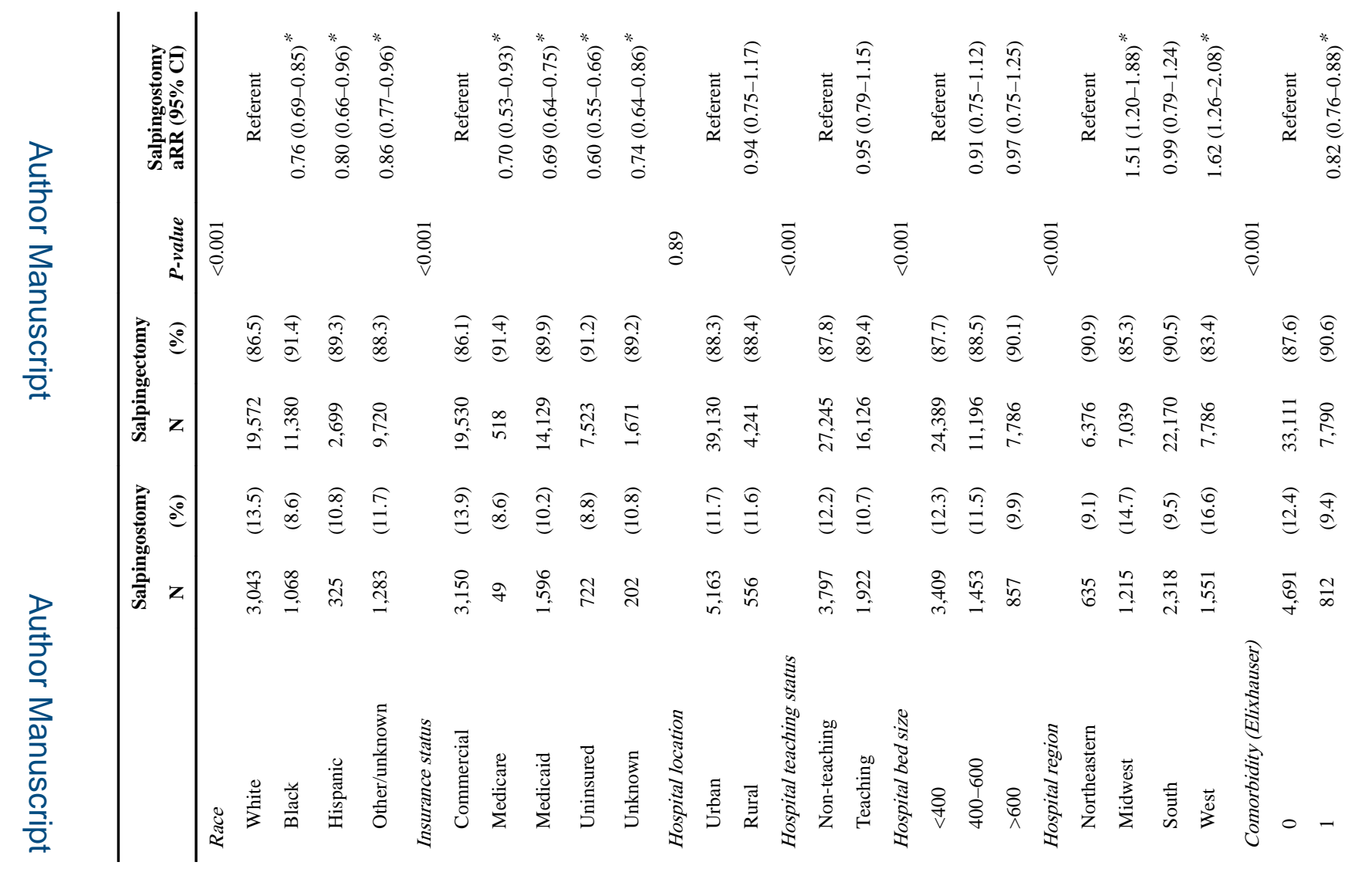

로을

로을

Am J Obstet Gynecol. Author manuscript; available in PMC 2018 July 01. 
HSU et al.

Page 15

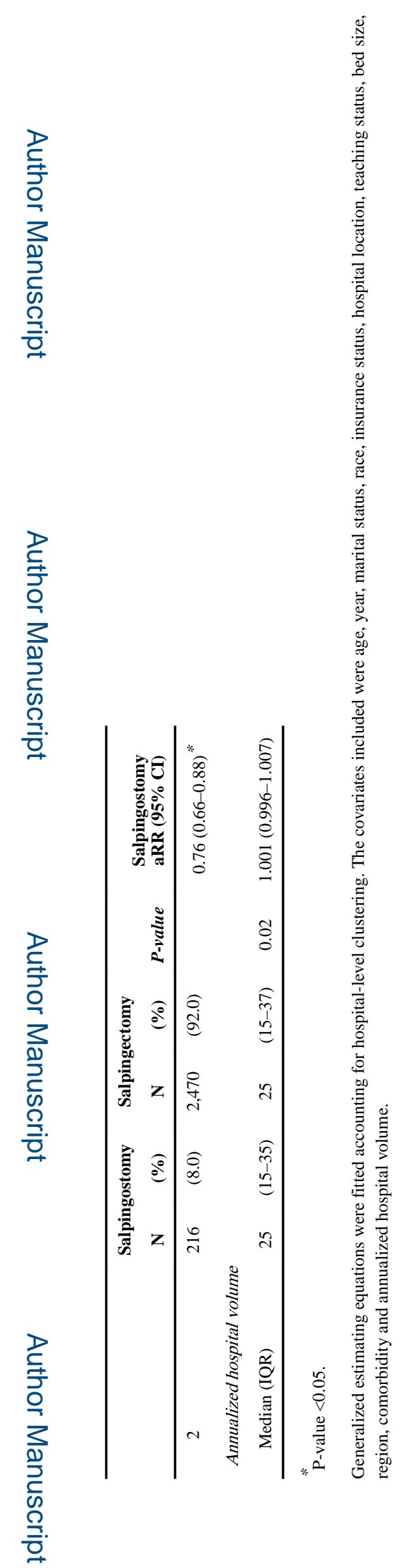

Am J Obstet Gynecol. Author manuscript; available in PMC 2018 July 01. 


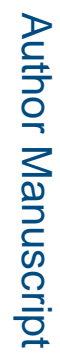

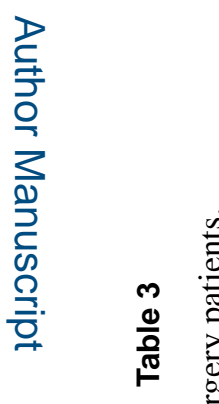

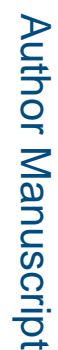

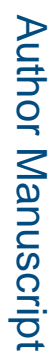

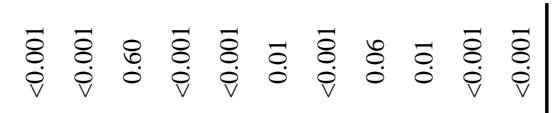

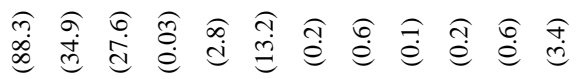

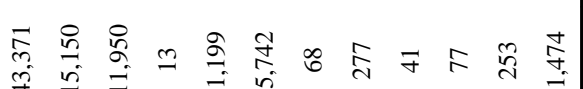

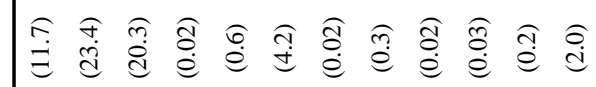




\section{Table 4}

Multivariable model of factors associated with complications among surgery (salpingectomy or salpingostomy) patients.

\begin{tabular}{|c|c|}
\hline & $\begin{array}{c}\text { Any Complication } \\
\text { aRR }(95 \% \text { CI }\end{array}$ \\
\hline \multicolumn{2}{|l|}{ Surgery } \\
\hline Salpingectomy & Referent \\
\hline Salpingostomy & $0.69(0.65-0.73)^{*}$ \\
\hline \multicolumn{2}{|l|}{ Age } \\
\hline$<20$ & Referent \\
\hline $20-24$ & $0.87(0.82-0.93)^{*}$ \\
\hline $25-29$ & $0.88(0.83-0.93)^{*}$ \\
\hline $30-34$ & $0.86(0.81-0.91)^{*}$ \\
\hline $35-39$ & $0.86(0.81-0.92)^{*}$ \\
\hline $40-44$ & $0.88(0.81-0.95)^{*}$ \\
\hline$\geq 45$ & $1.01(0.81-1.26)$ \\
\hline \multicolumn{2}{|l|}{ Year } \\
\hline 2006 & Referent \\
\hline 2007 & $1.00(0.95-1.06)$ \\
\hline 2008 & $0.98(0.91-1.04)$ \\
\hline 2009 & $1.03(0.97-1.10)$ \\
\hline 2010 & $0.98(0.91-1.05)$ \\
\hline 2011 & $1.03(0.96-1.10)$ \\
\hline 2012 & $1.01(0.95-1.07)$ \\
\hline 2013 & $0.99(0.92-1.06)$ \\
\hline 2014 & $1.02(0.95-1.10)$ \\
\hline 2015 & $1.03(0.93-1.14)$ \\
\hline \multicolumn{2}{|l|}{ Marital status } \\
\hline Married & Referent \\
\hline Single & $0.99(0.95-1.03)$ \\
\hline Other/unknown & $0.98(0.91-1.06)$ \\
\hline \multicolumn{2}{|l|}{ Race } \\
\hline White & Referent \\
\hline Black & $1.02(0.97-1.06)$ \\
\hline Hispanic & $1.15(1.07-1.24)^{*}$ \\
\hline Other/unknown & $1.13(1.08-1.20)^{*}$ \\
\hline \multicolumn{2}{|l|}{ Insurance status } \\
\hline Commercial & Referent \\
\hline Medicare & $0.94(0.83-1.05)$ \\
\hline Medicaid & $1.02(0.98-1.05)$ \\
\hline Uninsured & $1.12(1.07-1.17)^{*}$ \\
\hline
\end{tabular}




\begin{tabular}{|c|c|}
\hline & $\begin{array}{c}\text { Any Complication } \\
\text { aRR }(95 \% \text { CI) }\end{array}$ \\
\hline Unknown & $0.95(0.87-1.03)$ \\
\hline \multicolumn{2}{|l|}{ Hospital location } \\
\hline Urban & Referent \\
\hline Rural & $0.91(0.82-1.01)$ \\
\hline \multicolumn{2}{|l|}{ Hospital teaching status } \\
\hline Non-teaching & Referent \\
\hline Teaching & $0.92(0.85-0.99)^{*}$ \\
\hline \multicolumn{2}{|l|}{ Hospital bed size } \\
\hline$<400$ & Referent \\
\hline $400-600$ & $0.98(0.90-1.07)$ \\
\hline$>600$ & $1.08(0.97-1.21)$ \\
\hline \multicolumn{2}{|l|}{ Hospital region } \\
\hline Northeastern & Referent \\
\hline Midwest & $0.90(0.79-1.02)$ \\
\hline South & $0.95(0.85-1.06)$ \\
\hline West & $1.04(0.93-1.17)$ \\
\hline \multicolumn{2}{|l|}{ Comorbidity (Elixhauser) } \\
\hline 0 & Referent \\
\hline 1 & $1.49(1.44-1.55)^{*}$ \\
\hline$\geq 2$ & $1.68(1.60-1.77)^{*}$ \\
\hline Annualized hospital volume & $0.998(0.996-1.0004)$ \\
\hline
\end{tabular}

Generalized estimating equations were fitted accounting for hospital-level clustering. The covariates included were type of surgery, age, year, marital status, race, insurance status, hospital location, teaching status, bed size, region, comorbidity and annualized hospital volume. 